\title{
Proyecto de reforma de la Ley municipal y provincial en Italia
}

El proyecto de nueva Ley municipal y prcvincial italiana lleva larga gestación. A pesar del cuidadoso trabajo de una Comisión compuesta por relevantes personalidades de la Pclítica, de la Administración $y$ de la Cátedra, el Ministerio del Interior ha tenido que llevar a cabo un prolcngado examen del provecto $y$, por fin, ha considerado oportuno no presentarlo al Parlamento; por cl contrario, a petición de la Asociación Nacional de Municipics y de la Unión de Provincias, ha decidido abrir información pública sobre el proyecto.

Los primeros comentarios reconccen la ingente labor rea.izada por la Comisión, pues el estado de la legislación municipal y piovincial italiana es verdaderamente farragoso. Pero, aun $\mathrm{ccn}$ frases laudatorias para los altos funcionarios, magistrados y catedráticos, todos tllos expertísimos en materia administrativa, parece que se hubiera deseado la participación de funcicnarios cualificados de las Entidades locales. En efecto, la Ley de 1915, que ha servido de punto de partida, contemplaba una vida plácida, tranquila, no inquietada, ccmo ahora, por las rivalidades electorales $\mathrm{y}$ las necesidades crecientes de todo crden. $\mathrm{Y}$ hubiera convenido-afirman algunos comentaristas- la incorporación de personas más cercanas a la vida de Municipios y Provincias, a las actividades de ámbito local, lo que habría permitido el estudio de una refcrma de vasto a.cance y de vital interés para las Entidades locales.

El problema inicial más debatido en la propia Comis:ón redactora, fué sobre el mismo ámbito del proyecto. ¿Debía abarcar la Región, la Provincia y el Municipio? Hay, sin duda, un estrecho paralelismo entre las esferas regional, provincial y municipal; a!- 
gunas materias podrían haber sido objeto de tratamiento unitario, común a las tres esferas. Sin embargo, como explica la exposición de motivos, la realidad es que hoy, en Italia, la Región es un ente de rango ccnstitucional, con distinto relieve, de natura:eza diferente a la de los otros Entes territoriales. Por eso prevaleció el criterio de prescindir del ordenamiento regional, y circunscribir el proyecto al tradicicnal ámbito de lo municipal y provincial exc.usivamente.

\section{ESTRUCTURA DEL PROYECTO}

Consta el proyecto de dcscientos cincuenta artículos, agrupados, salvo los preliminares, en siete títulos; algunos de éstos se dividen, a su vez, en capítulos.; estcs últimos nunca se subdividen, a pesar de que algunos son de gran extensión (treinta y cuatro artícuios tiene el VIII del título III) y abarcan materias un tanto heterogéneas.

La sistemática corresponde a la habitual de leves anteriores. Difiere bastante de las leyes españolas, que, en iste aspecto, han lcgrado alcanzar - sin que ello sea pretencioso- una construcción ajustada al mayor rigor científico. Se nota, en general, cierta timidez para prescindir de antiguos moldes, y regu'ar de modo unitario aquellos aspectos que formalmente son comunes a todas las Entidades locales; han preferido los autores utilizar abundancia de reenvícs y dejar sólo, para las disposiciones comunes a todas las Entidades, un mínimo de proyectos.

Las disposiciones finales y transitorias constituyen un título, el séptimc, con articulado normal, lo que, innegablemente, faci.ita las referencias y refleja extremada uniformidad.

Los pocos comentarios que la sistemática ha suscitado en Italia han sido favorables, pues responde a criterios alli consagradcs. Es de esperar que algunos detalles defectucsos, sobre todo visibles en el título IV, serán fácilmente subsanados.

Para resumir, a grandes líneas, el esquema formal del proyecto, indicaremos sólo que, después de siete artículos colccados bajo la rúbrica de adisposiciones preliminaresn, los distintos títulos son ios siguientes:

Título I.-Circunscripciones municipales y provinciales.-Autoridades gubernativas. Consta de seis artículos.

Título II.-Organo regional de control sobre lcs actos de las Entidades locales. Consta de doce artículos. 
Titulo III.-El Municip:o. Comprende ciento treinta y seis artículos, encuadrados en cnce capítulcs, en la siguiente distribución de materias: Alteraciones de las circunscripciones municipales; la Administración municipal ; el Consejo municipal ; la Junta municipal; el Alcalde; publicación de los acuerdos; controles sobre los actos municipales; hacienda y contabilidad; responsabilidad de los Administradores y dependientes del Municipio, y acción popular; los dependientes del Municipio; las infracciones de Reglamentos y Ordenanzas.

Título IV.-La Provincia. - La Administración provincial. Comprende treinta y cuatro artículos; los tres primeros sueltos, y lcs otro treinta y uno, agrupados en cuatro capítulos. El primero de éstos trata del Consejo provincial. El segundo, de la Diputación. Fl tercero, del Presidente de la Diputación. El capítulo IV abarca todas las materias ya tratadas paralelamente, en la esfera municipal, por los capítrilos VI al XI del títula III, y a cuyos preceptos se remite.

Título V.-Las Mancomunidades entre Municipios y Provincias. Lo integran trece artículos.

Título VI.-Disposiciones comunes a la Administración municipal, provincial y mancomunada. Consta de treinta y cinco artículos, distribuídos en cuatro capítu'os, con las siguientes materias: Circunscripciones ierritoriales y representación ; sesiones y acuerdos ; ejercicio, por los Municipios, Prcvincias y otras Entidades locales, de funciones del Estado y de la Región; gestiones extraordinarias.

Título VII.-Disposicicnes finales y transitorias. Integrado por seis artículos.

\section{LAS DISPOSICIONES PRELIMINARES}

Los siete artícuios iniciales del proyecto, agrupados bajo el epígrafe de disposiciones preliminares, contienen preceptos fundamenta'es sobre régimen jurídico: anulación y revocación de actos administrativos, y recursos contra éstcs.

La propia Administración, en principio, puede anular sus actos, por ilegalidad de los mismos. Tiene competencia para ello, dentro del términc de un año, la propia Autoridad de que emanaron - la Autoridad jerárquica superior; el Presidente de la República 
puede asimismo anularlos por dos motivos: incompetencia y violación de ley.

También puede la Administración revocar sus propios actos cuando tienen vicios $d \imath$ merito, o por alteración de las circunstancias ce hecho, o por nuevas exigencias del interés público. Compete la revocación a la misma Autoridad de que emanó el acto, o a la jerárquicamente superior.

Normalmente, los efectos de la anulación y de la revocación por vicios di merito se retrotraen a la fecha del acto; en cambio, la revocación pcr. alteración de las circunstancias de hecho o por nuevas exigencias del interés público no surten efecto retrcactivo.

No deben anularse ni revocarse los actos cuando ello resuite abiertamente contrario al interés públicc o a la equidad. $Y$ en ningún caso pueden ser objeto de anulación ni revocación las resoluciones declaratorias de capacidad, poderes o derechos.

En cuanto a recursos, es principio general que los actos no son recurribles ante la misma Autoridad de que emanaron, y que las resoluciones de las Autoridades gubernativas inferiores son recurrib'cs ante el superior jerárquicu. Los recursos que las leyes italianas denominan genéricamente aante el Gobiernon, pueden ser resueltos pcr el Ministro correspondiente, salvo que la resolución recurrida hubiese emanado de él mismo, en cuyo caso, previa deliberación del Consejo de Ministros, se resolverá el recurso mediante decreto.

\section{AUTORIDADES GUBERNATIVAS Y ORGANO REGIONAL DE CONTROL}

El título I configura el cargo de Prefecto de modo muy similar al de nuestro Gobernador civil. Vigla la marcha de la Administración en general; coordina la actuación de la central y la local ; promueve la decisión de competencias entre los órganos administratives y los jurisdiccionales; tutela el orden público y la seguridad coiectiva; dispone de la fuerza pública y puede pedir la intervención de otras fuerzas armadas. De los actos realizados en el ejercicio de su cargo sólo responde ante la superior autoridad administrativa, y no puede ser procesado sino con autorización del Presidente de la República, oído el Consejo de Estado.

En cada Provincia hay un Prefecto, un Viceprefecto que lo sus- 
tituye en caso de vacante, ausencia o impedimento, y una cficina de Prefectura.

Mayor novedad ofrece para nosotros el órgano regional de control, de que trata el título II. Son las llamadas Ccmisiones provinciales de contro!, compuestas por nueve miembros : cinco de ellos, especialistas en materias administrativas, nombrados por el Consejo regicnal cada cuatro años, entre quienes figuran en las listas electorales de cualquier Municipio de la Regićn; los otros cuatro, designados por el Comisario gubernativo regional (dos del escalafón administrativo del Ministerio del Intericr, uno de la escala de contabilidad del mismo Ministerio y uno de la escala de Hacienda).

Estas Comisiones provinciales - como luego se va viendo en el articulado del proyecto- ejercen ccntrol de legalidad sobre todos ios actos municipales, e incluso control di merito sobre los más importantes, que el propio proyecto va enumerando.

El control de legalidad llega hasta la anulación de los acuerdos municipales, cuando implican violación de ley. $\mathrm{Y}$ para hacer posible tal control tcdos los acuerdos deben ser puestos en conocimiento de la Comisión en el plazo máximo de ocho días; en principio, ningún acuerdo es. ejecutivo hasta que la Comisién provincial lo haya visado, o hayan transcurrido veinte días sin formular reparos al mismo, aun cuando, sin perjuicio de someterlo a control, puede declarar el Consejo municipal su inmediata ejecutividad, con el voto de la mayoría abso'uta.

El contrcl di merito se ejerce en forma análoga al de legalidad, aun cuando su alcance es distinto. En primer lugar, sólo se sujetan al control di merito determinados actos, los más importantes o de mayor trascendencia, verbigracia, la aprobación del fresupuesto, las transferencias de créditc entre capítulos distintos, la imposición de exacciones, la constitución de Mancomunidades, las enajenaciones, los Reglamentos y Ordenanzas, la asunción directa de servicios públicos, los planes de urbanización, el señalamiento de indemnizaciones, por razón del cargo, al Alcalde y Terientes de A'calde, etc. Pcr otra parte, las facultades de la Comisión, en este aspecto, se reducen a requerir al Municipio para que reexamine lo acordado; si el acuerdo se ratif:ca, necesita el voto favorable de la mayoría absoluta para ser ejecutivo.

El control de los servicics delegados por el Estado en los Municipios se rige por leyes especiales; y para e! contiol en las materias delegadas por la Región, la Comisión funciona solo con siete miembros (tres del primer grupo ind:cado y lcs cuatro del segundo). 
También están facultadas las Comisiones de control para disponer inspecciones circunstanciales o periódicas, a fin de comprobar si en la marcha de les servicios se observan las leyes y reglamentos.

En alguncs casos concretos tienen incluso funciones di sustiturión, pudiendo adoptar decisiones cuando los órganos del Muniripio omitan acuerdos o actos obligatorios.

\section{EL MUNICIPO Y SUS ORGANOS}

Dice el proyecto que ael Municipic es ente autónomo, con fun. ciones administrativas propiass, y que atambién ejerce, por delegación de la Región, funciones administrativas de éstan.

Los órganos del Municipio son el Consejo municipal, la Junta municipal y el Alcalde, que, con las naturales diferencias, equivalen a nuestro Ayuntamientc, Comisión permanente y Alcalde.

El Consejo muricipal es mucho más numeroso que nuestio Ayuntamiento: el número de consejeros va de quince (en los Municipios de menos de 3.000 habitantes), hasta ochenta (en los de más de 500.000 habitantes). En los Municipios minúsculos -también los hay en Italia-, cuando el número de elegibles no excede de quince, todos ellos son consejeros. No contiene el proyectc: alusión alguna al sistema de elección, que se rige por las leyes electorales.

La Junta municipal que, a diferencia de nuestra Comisión permanente, existe en todos los Municipios, pcr pequeño que sea su censo de población, se compone del Alcalde, que ia preside, y de vn número variable de vocales, que va desde cuatro (en los Municipios que no exceden de 10.000 habitantes) hasta catorce (en los Municipics de más de 500.000 habitantes). Los vocales de la Junta son elegidos por el Consejo municipal, de entre los propios conseieros.

El Alcalde tiene, como en España, el doble carácter de Jefe de la Administración municipal y delegado del Gobierno. Es elegido siempre por el Consejo municipal. Los Tenientes da Alcalde, que lo sustituyen en casos de vacante, ausencia o impedimentc, tienen igual consideración que el titular en el ejercicio de sus funciones. Como distintivo externo, el Alcalde usa una banda tricolor, con el escudo de la República.

Cuando existan poblados o núcleos alejados de la capitalidad del Municipio, y con dificultades de comunicación, el Alcalde puede 
celigar sus funciones en cualquier vecino elegible para consejero, que resida en e: núcleo.

Los Munic:pios con pablación suparicr a 60.000 habitantes, aun cuando no tengan núcleos o poblados alejados del casco urbano, pueden ser divididos en barr:os, per acuerdo del Consijo municipal, y, in tal caso, también puede el Alcalde delegar sus funciones en la forma indicada.

Es cbligatoria la residencia de un delegado del Alcalde en las Eintidades menores - con patrimonio separadc-, que asume las funciones de delegado del Gobierno y vela por la observancia de los acuerdos municipales.

La distribuc:ćn de competencias entre el Consejo, la Junta y el Alcalde responde al criterio normal de mayor a menor importancia de los actos.

Así, competen al Consajo las funciones fundamentales de orgarizar las oficinas y servicios municipales; el nombramiento y sanción de los empleados y resoluciones sobre la situación de los mismos; aprobar el presupuesto y las cuentas, las transferencias de créditos entre capítulos distintcs del Presupuesto etc., etc. Como principio general expreso, se le atribuyen todos los asuntos que no ctan de la competencia de la Junta o del Alcalde.

A la Junta municipal le están atribuídas, más que nada, funciones preparatorias de lcs acuerdos del Consejo, cuyas sesiones y orden del día señala ella misma; también se le confieren atribuciones de menor importancia, como el nombramiento de personal asalariado transferencia de créditos dentro del mismo capítulo del Presupuesto, entablar las simples acciones posesorias, etc., y en los srandes Municipios se le otorga facultad para celebrar contratos y realizar actos de disposición que no excedan de determinado importe (que el proyecto fija detalladamente, según el censo del Municipio) y duración; acuerdos y actos que debe comunicar al Consejo en la primera sesión que éste celebre. Por último, puede adcptar, en casos de urgencia, acuerdos de la competencia del Conșejo, que éste ha de ratificar en la primera sesión que celebre.

Al Alcalde se le reservan facultades eminentemente ejecutivas, $\mathbf{y}$ las representativas del Municipio; también puede apercibir y suspender preventivamente a los empleados y asalariados. Como delegado del Gcbierno, le compete, por otra parte, velar por el orden públicc, la seguridad e higiene; la marcha del Registro civil y del censo de población.

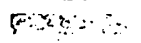


Prevé el proyecto el cese de los titulares de los distintos órganos, en concordancia con el criterio general que lo inspira. Así el Alcalde puede ser removido por acuerdo del Consejo, adoptado por mayoría abscluta. Cada uno de los miembros de la Junta, o todos cllos, pueden ser removidos por acuerdo del Consejo, adoptado también por mayoría absoluta. El Consejo municipal puede ser disuelto por decreto motivado del Presidente de la República, en los casos que prevé el proyecto: $11^{\circ}$, por violar grave o repetidamente la ley ; $2 .^{\circ}$, por no cumplir la indicación de las Autoridades gubernativas de remover a la Junta o al Alcalde que hubieren comeido tales violaciones, y $3 .^{\circ}$, pcr no poder funcionar debido a falta de ccnsejeros. Para el período que transcurra hasta la elección y constitución del nuevo Consejo municipal, se prevé como órgano extraordinario de gestión una Comisión de tres miembrcs, que asume las funciones normales de la Junta municipal $y$, en los asuntos inaplazables, las del Consejo, y cuyo Presidente asume, a su vez, Ias funciones de Alcalde. En los Municipios de menos de 25.000 kabitantes, se prevé el posible nombramiento de un gestor unico.

\section{LOS DIVERSOS ASPEC'TOS DE LA ACTIVIDAD MUNICIPAL}

A fin de no romper de modo rotundo la trayectoria del proyecto, nos vemos ub.igados a reunir en este epígrafe conjuntc: la mayoría Je los aspectos fundamentales que abarca el capítulo VIII del título III. Efectivamente, en él se comprenden - y nos ha extrañado un tanto-, sin subdivisión sistemática alguna, preceptos sobre patrimonio, contratación, obras, servicios y Hacienda. Procuraremos, como en los epígrafes anteriores, agrupar, por materias, las iineas fundamentales del proyecto.

a) Bienes. Se clasifican en demaniales y patrimoniales. Los inmuebles patrimonia'es deben ser, normalmente, dados en arriendo; pueden ser dados en aprcvechamiento comín cuando las condiciones especiales del lugar lo exijan, pero siempre mediante canon que no podrá ser inferior a los gastos que al Municipio le supongan tales bienes.

Las inversiones en valores mobiliarics deben ser en títulos nominativos emitidos por el Estado o con garantía de éste. Está pro. hibida la adquisición de deuda pública exterior. 
$\mathrm{E}_{i}$ invertario de tchos los bienes de cada Municipic debe estar. siempre al día; y deba existir invertario separado para cada establecimiento o institüción ảeperdiente del Municipio, y para las Entidades menores con patrimonio propio.

La enajenación de bienes, la constitución de servidumbres y enfiteusis están sujetcs al control di merito por la Comisión provincial de control, salvo que sean de valor inferior al que señala el proyecto, sagún escala en relación con è censo de población.

b) Contratación. Como sistema normal de contratación, se establece la subasta pública. Se permite la licitación privada, cuando el ccntrato verse sobre cantidades inferiores a las que el proyecto establece, $\mathrm{y}$, además, cuando el Consejo municipal lo acuerde por mayoría absoluta. También puede el Consejo acordar, por mayoría absoluta, la contratación directa en los cascs de necesidad o conveniencia para el Municipio.

Para las cbras o suministros que exijan técnica o medios especiales, el Consejo también puede acordar, por mayoría absoluta, invitar a las empresas especializadas a presentar prcyectos y condiciones de ejecución. La resolución, previo examen, cuya modalidad será prefijada en el acuerdo, puede tener en cuenta los elementos técnicos y económicos de cada oferta e incluso las garantías de capacidad y seriedad de cada empresa.

El Secretario está facultado para extender, en exc.usivo interés de la Administración municipal, los ccntratos y las actas de subastas.

Los Municipics de más de 30.000 habitantes o capitales de Provincia, deberán tener un pliego general de condiciones de contraración.

c) Hacienda. Uno de los aspectos fundamentales en la materia - los ingresos - no se aborda en el prcyecto; éste se limita a decir que las exacciones municipales serán previstas y regu'adas por leyes especiales. Faltando tema de tan primordial interés veamos algunos otros extremos.

Enumera el proyecto los gastos obligatorios por este orden: los de conservación del patrimonio; oficina y archivo municipal; haberes del perssnal; servicios de interés estrictamente local, y funciones impuestas, en general, por la Ley. Y como gastos vcluntarios, cuando el presupuesto lo permita, se conceptúan los demás que se destinen a costear servicios y oficinas de utilidad pública, en relación con lcs intereses locales. 
Nota interesante es que los servicios de Tesorería pueden conrertarse con la Caja de depósitos y préstamos, las Cajas de Ahorro, el Banco de emisión o los Institutos de créditc de derecho público o interés nacional. El convenio habrá de especificar las normas para el ccntrol de las ingresos, la situación de las cuentas corrientes y el pago de los mandamientos.

Las cuentas de cada ejercicio deben ser redactadas por el Tesorero dentro del primer cuatrimestre del añc siguiente; el Alcaldo las somete a dos revisores (elegidos por el Consejo entre sus miembros no designados para formar la Junta municipal), que han de efectuar la revisión en el término de dos meses ; el Ccnsejo municipal adopta el acuerdo pertinente sobre su aprobación, y se pasan a. conocimiento de la Comisión provincial de control. Si la Comisión provincial observá en ellas alguna irregularidad, da cuenta al organo jurisdiccional contable de la región, para el fallo que proceda, que es recurrible ante el Tribunal de Cuentas.

Por lo que respecta a las operaciones de crédito, establece el proyecto determinadas limitaciones: ha de estar garantizada la amortización; debe tener por objeto la financiación de gastos extraordinarios, y el acuerdo ha de adoptarse por mayoría absoluta de hecho del Consejo municipal. La emisión de títulos requiere, además, la previa autorización del Ministro de Hacienda, de acuerdo ron el del Interior, oída previamente la Comisión provincial de control.

\section{EL PERSONAL DE LOS MUNICIPIOS}

Bajo el concepto genérico de dependientes municipales se comprenden los empleados y los asalariados. El proyecto se limita a sentar unas cuantas normas generales, a hacer los pertinentes reenvíos a la legislación de funcionarios del Estado y a encomendar a los Reglamentos especiales de cada Municipio la regulación detallada del estatuto de sus dependientes.

$\mathrm{El}$ ingreso de los empleados administrativos y técnicos ha de tener lugar por ccncurso público juzgado por una Comisión calificadora designada por el Consejo municipal; los nombramientos han de ajustarse al riguroso orden de calificación establecido por la Comisión.

Las ccndiciones generales de capacidad para el ingreso como empleado o como asalariado son las normales de ciudadanía, buena 
conducta, condiciones físicas, etc.; las edades son un poco más bajas, pues se señala la mínima de dieciocho años y la máxima de treinta, que se amplía a treinta y cinco cuando se exige título superior.

Las incompatibilidades generales son en extremo rigurosas, pues comprenden no șólo otrọs empleos retribuídos del Estado o de los Entes públicos, sino también cualquier empleo prívado, el ejercicio de profesiones, comercio o industria, y la condición de administrador, consejero o síndico - aunque sea sin retribución- en cualquier sociedad constituída con fin de lucro.

En materia disciplinaria, el proyecto se remite a la legislación de funcionarios civiles del Estado, aun cuando recalca que ninguna sanción puede ser impuesta sino mediante resolución motivada, pliego de cargos, etc. Las sanciones más graves no pueden aplicarse sin previo informe de la Comisión de disciplina, cuya composición se prevé con cinco miembras : dos consejeros municipales, el Secretario y dos empleados.

El cese se regula con evidente amplitud de motivos. El licenziamento puede acordarse por supresión del cargo o reducción de la plantilla. La dispensa, o despido, que ha de decidirse por resolución motivada, con audiencia del interesado, puede estar motivado por imposibilidad física, por incapacidad profesional y por escaso rendimiento. $Y$, por ́ultimo, cuando se descubra que un funcionario consiguió su ingreso en vịtud de documentos falsos, o mediante otros actos fraudulentos, incurrirá en licenziamento con pérdida de derechos pasivos y de toda indemnización.

Se deja en libertad la fijación de sueldos y salarios, indịcando, sin embargo, el proyecto, que se deberán establecer en proporción equitativa con el del Secretario, teniendo en cuenta además la situación financiera del Municipio, las condiciones económicas de la localidad, los requịsitos exigidos para el ingreso, la naturaleza e importancia del servicio, la relación entre los diversos grados jerárquicos, y demás elementos de juicio. El propio precepto prohibe a los Municipios asumịr a su cargo las cuotas que el personal deba satisfacer por su afiliación a la Caja de previsión o por otras obligaciones derivadas de la Ley. 


\section{RESPONSABILIDAD DE LOS ADMINISTRADORES $\mathrm{Y}$ DEPENDIENTES MUNICIPALES}

Lcs Administradores y dependientes del Municipio, o de Instituciones o Establecimientos municipales, resarcirán al Ente los daños que le irroguen con dolo o culpa. Si el hecho es imputable a. varios, responderán solidariamente, y cuando sea desigual lai respensabilidad, por las diferentes atribuciones y deberes de los distinios cargos, cada uno responderá de la parțe que le corresponda.

Según el proyecto, se hallarán exentos de responsabilidad los mie.nbros de los órganos deliberantes que no hayan tomado parte en la adopción del acuerdo, por causa justificada, así como quienes b.ry ian hecho constar su voto en contra, o haber formulado reclamación o propuesta para evitar el acuerdo o acto del que haya derivado el daño. También están exentos de responsabilidad los depen. dientes (empieados, asalariados) que hayan actuado en virtud te obediencia debida. No responden tampoco los superiores jerárquicos por el daño que su subordinado cause en el ejercicio de sus funciones, siempre que en el destino del mismo a sus brdenes no se hubiere ccmetido grave infracción de Ley y que el superior no sea graremente culpable en cuanto afecte al deber de vigilancia.

I.a acción de responsabilidad contra los administradores la promueve la Comisión provincial de control ; contra los dependientez puecie promover'a el Alcalde, previo acuerdo del Consejo municipal, y también la Comisión de control si el Municipio uv procediere a ello.

\section{MULTAS}

Dedicamos un apartado especial a esta materia -el proyecto lo dedica un capítulo-, por el interés que pueden tener las modalidarles de imposición de esta sanción pecuniaria.

Como norma general, prevé el proyecto que la infracción de los Reglamentos y Ordenanzas municipales, y de los bandos del Alcalḋs se castiga con multa que puede llegar hasta cinco mil liras.

La imposición de la multa puede tener lugar de dcs formas: una que calificamos de inmediata y genérica, y otra que cabría denominar mediata e individualizada.

La imposición inmediata y genérica se lleva a cabo directamente, por el agente o funcionario que ha observado la infracción, 
cuando la cuantía de la multa está prefijada en bandos gue han tenido que ser publicados previamente.

La imposición mediata e individualizada tiene original tramitación: se comunica al infractor la contravención que ha cometido, indícándole debe solicitar del Alcalde el señalamiento de la multa, dentro de los límites establecidcs por la Ley; el Alcalde puede negarse al señalamiento de la multa, cuando la contravención haya causado daño a un tercero, o al Municipio, mientras el culpable no indemnice previamente a aquél, o repare los efectọs de la transgresión. Si el infractor no pide el señalamiento de la multa en el plazo que al efecto se le concede (diez días, por lo general), o el Alcalde se ha negado a tal señalamiento, por no haber sido indemnizado el tercero, o reparados las efectos de la transgresión, o și efectuado el señalamiento de la multa ésta no hubiese sido pagada, el Alcalde pasa el tanto de culpa al Juez de primera instancia y el infractor queda incurso en procedimiento penal.

Las sumas recaudadas por multas pasan a las arcas municipales, pero un tercio se reintegra a un fondo especial para premiar a los agentes encargados de la imposicion de aquéllas.

\section{LA PROVINCIA Y SUS ORGANOS}

Paralelamente al Municipio, el proyecto define a la Provincia como Ente autónomo, con funciones administrativas propias; también ejerce funciones administrativas delegadas dẹ la regibn, y puede, asimismo, asumir servicios de interés local, dentro de su circunscripción, mediante concierto con otros Entes públicos.

Organos de la Provincia son el Consejo provincial, la Diputasion provincial y el Presidente de la Diputación; estructura triorgánica paralela de la municipal, aun cuando con algunas divergencias, ya que el Consejo funciona un poco independizado, con Presidente, . Vicepresidentte, Secretario y Vicesecretario propios, renovables todos los años y distintos de los de la Diputación, hasta el punto de que el proyecto establece la incompatibilidad entre el cargo de Presidente del Consejo provincial y. el de Presidente de la Diputación.

El Consejo es bastante numeroso, de 30 a 60 miembros, segin el censo de población de la Provincia; ha de reunirse tres veces al año, y puede hacerlo también por acuerdo de la Diputación, o a peticion de una tercera parte de los consejeros. 
La Diputación está integrada por 6 a 10 Diputados, según el renso de población, designados por el Consejo entre los propios consejeros, y pueden ser removidos en todo momento por el mismo Consejo.

El Presidente de la Diputación es designado también por el Consejo provincial, entre los consejeros.

La distriburión de competenciäs entre los tres órganos de la Provincia responde a criterios muy parecidos al de los tres órganos del Municipio.

En los demás aspectos de la Administración provincial, el proyecto se remite a lo previsto para la Administración municipal.

\section{LAS MANCOMUNIDADES O CONSORGIOS}

Como principio general, tanto los Municipios, entre sí, como las Provincias, como unos y otras recíprocamente, pueden mancomutarse para servicios de interés común. De tales Mancomunidades o Consorcios jueden formar parte, asimismo, otras Entidades públicas.

El proyecto se limita a unas pocas normas fundamentales sobre la materia, ya que los Estatutos de cada Mancomunidad habrán de contener las; disposiciones pertinentes sobre el nombre, los fines, la sede, la ducación, los órganos, la contribución de cada Ente, etc.

Las Mancomunidades son personas jurídicas públicas, cuyo reconocimiento corresponde: al Prefecto, si todos los Entes mancomunados pertenecen a la misma Provincia; al Comisario gubernativo regional, si pertenecen a Provincias distintas, y. al Ministro de Interior si pertenecen a diferentes Regiones.

Con carácter preceptivo, toda Mancomunidad tendrá una Asamblea, un Consejo directivo y un Presidente ( $\sin$ embargo, cuando no sea necesario, cabrá prescindir del Consejo directivo), y los representantes han de renovarse cada cuatro años como máximo.

Para su servicio, pueden las Mancomunidades tener personal propio o utilizar el de los Entes mancomunados.

\section{NORMAS GENERALES COMUNES}

A TODAS LAS ENTIDADES

Han sido muy parcos los autores del proyecto en nutrir el título VI, que contiene disposiciones comunes a Municipios, Provin- 
cias y Mancomunidades. Ya lo indicamos al principio de este camentario. De las variadísimas normas comprendidas en el título, las que pueden ofrecer mayor interés son las relativas a representación y al régimen de sesiones y acuerdos.

a) Representación. E1 mandato de las consejeros, tanto municipales como provinciales, dura cuatro años; transcurridos éstos, \&l Consejo se renueva por completo. Ahora bien, tal mandato, a pesar de su duración definida, se prorroga hasta el momento misma en que asumen el suyo los nuevos elegidos. (Juando, dentro del período de mandato normal, se produce vacante, y se procede a la elección de quien sustituya al Consejero que ha causado baja, el mandato del sucesor sólo dura lo que el del antecesor.

Son bastantes los casos en que la Ley ailude al miembro más rantiguan (anziano), y el propio proyecto no:s define lo que es esa antigüedad (anzianitá) : está representada, jrimero, por la fecha de la elección; para los elegidos en la misnia fecha, por el mayor numero de votos, y para los que han obtenido igual numero de votos en la misma elección, por la mayor edad.

Se recoge, como motivo de cese, la falta de asistencia a determinado número de sesiones consecutívas (seis o tres, según el órgano y el numero legal de sus miembros) ; cese que ha de ser acorJado por el Consejo respectivo, previa audiencia de los interesados.

También cabe el cese voluntario por dimisión, que ha de ser presentada ante el Consejo respectivo y aceptada por éste; en raso de silencio, o de no aceptación, el dinnisionario puede acudir ante la Comisión provincial de control.

Por razón del cargo, pueden percibir indemnizaciones el A1calde, el Presidente de la Diputación, los crmponentes de las Juntas municipales y de la Diputación provincial, pero tales indemnizaciones son incompatibles con cualesquiera otras asignaciones a rargo del Estado o de otras Entidades públivas.

b) Sesiones y acuerdos. Se establece el principio general de la pubficidad de las sesiones del Consejo. J'ara su celebración en primera convocatoria, se requiere la asistencia de la mayoría; en segunda convocatoria ha de asistir un numero mínimo que señala el proyecto en cada caso, $y$ que viene a ser tras poca variacion, ligeramente superior a un tercio de los miembros. Entre la primera y la segunda convocatoria han de mediar, por lo menos, veinticuatro horas. Tales números mínimos de assistentes han de reflejarse en los acuerdos, $y$, por consiguiente, no se cuentan como asis- 
tentes los que se ausentan en el momento de la votacion ni los que han de abstenerse por tener interés en el asunto. A su vez, los acuer¿̇os han de reunir mayoría de presentes, salvo que la Ley exija mayoría especial; y no se permite segunda votación inmediata sobre el mismo asunto, salvo los casos en que así esté dispuesto (casos, normalmente, de elección de personas para cargos determinados).

Las propuestas han de ser presentadas por el Presidente o por los miembros del brgano respectivo; unas y otras han de figurar en el orden del día, en el que se relacionan, primero, las del Pro sidente, y, a continuación, las de los demás miembros.

Durante la celebración de las sesiones tiene el Presidente amplios poderes discrecionales para mantener el orden, la observancia de la ley 7 la regularidad de los debates y acuerdos, y está facultado para suspender y levantar la sesíbn y para expulsar al público que perturbe el orden,

Corresponde al Secretario levantar acta, debiendo reseñar en la misma los puntos principales objeto de discusión y el número de votos en pro y en contra de cada propuesta. Las actas han de ser aprobadas en sesión, pero sólo han de firmarlas el Presidente, el miembro más antiguo y el Secretario.

En casos concretos, pueden los brganos deliberantes encomendar las funciones de Secretario a uno de sus propios miembros, para deliberar sobre tal o cual asunto; en ta!es casos, el Secretaria titular debe ausentarse del salon durante el debate y la adopcion del acuerdo, pero todo ello ha de reflejarse expresamente en el acta.

Carece de relîeve, para nosotros, el contenido de las disposiciones transitorias.

Con lo dicho puede formarse el lector una idea suficiente de las directrices $\mathrm{v}$ sentido del proyecto.

A. C. C. 